\title{
Planet unser, der Du bist im Himmel
}

\section{Erhard Taverna}

Dr. med., Mitglied der Redaktion

«Laudato si', mi' Signore, per sora nostra madre terra», tönt es im Sonnengesang des Bruders Franziskus. Seither sind fast achthundert Jahre vergangen, und die Erde rollt immer weiter aus dem damaligen Zentrum. Mutter Erde ist nicht mehr alleine, oder vielleicht doch?

Seit in Genf 1995 der erste Exoplanet Pegasi-51 b entdeckt wurde, sind über 3500 weitere dazugekommen, wovon 352 mit erdähnlichen Eigenschaften. Keppler-24 b im Sternbild Leier und Trappist-1 g im Wassermann sorgten für Schlagzeilen. Sie kreisen in einer habitablen Zone um ihre Sonne, könnten von Ozeanen bedeckt sein und eine Atmosphäre aufweisen. Der nächste Exoplanet, Proxima Centauri-b, ist "nur» 2,4 Lichtjahre entfernt. Er wurde im letzten Jahr entdeckt, und schon sucht eine private Organisation Sponsoren für einen Erkundungsflug. Mit jedem neuen Teleskop werden weitere Trabanten dazukommen, und die Analyse ihrer Beschaffenheit wird sich verfeinern. Die Sowjetunion experimentierte ab 1965 in Sibirien mit sogenannten bioregenerativen Lebenserhaltungssystemen. Bios-3 war ein Treibhaus, in dem drei Kosmonauten, mit 180 Tagen, die längste Zeit verbrachten. Marsflüge schienen in greifbarer Nähe. Nach den ApolloMissionen und der ersten Mondlandung 1969 dauerte es bis 1991, bis ein Ölmilliardär in der Wüste von Arizona im grösseren Massstab einen hermetisch versiegelten Gebäudekomplex errichten liess. Ein Ökosystem aus Glas und Stahl mit Miniaturregenwald, Ozeanpool und Anbauflächen, in dem beim ersten Versuch vier Männer und vier Frauen in kleinen Apartments zwei Jahre lang das Überleben trainierten. Laut einem Teilneh-

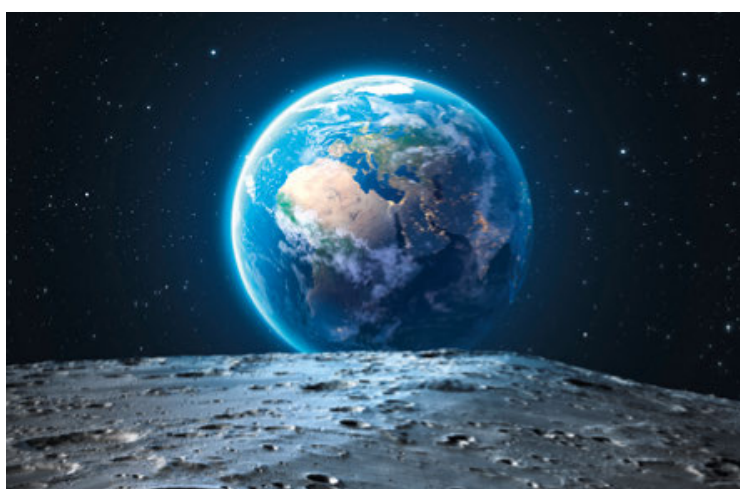

mer sollen Angst, Hunger, Ameisen und Kakerlaken den Bionauten das Leben schwergemacht haben. Depressionen mussten telefonisch behandelt werden. Ein zweiter Versuch wurde nach sechs Monaten aus technischen Gründen abgebrochen. Vermarktet wurde das Projekt als Auftakt zu einer ausserirdischen Besiedelung. Als die Schwierigkeiten sich häuften, sprach man von einer Insel für die Überlebenden eines Atomkrieges. Biosphäre-2 brachte viele Erkenntnisse zu Stoffwechsel-Kreisläufen in der Natur, die ein universitäres Labor mit der NASA weiterentwickelte. Teilnehmer träumen heute noch unbeirrt von einer Multi-Planeten-Spezies Mensch. Der amerikanische Schriftsteller T. C. Boyle, der oft Umweltthemen aufgreift, hat die Geschichte in seinem Roman "Terranauten" wiederaufgenommen, wobei ihn weniger die Technik, als Menschen in extremen Situationen interessieren. Eine Big-Brother-Show, angetrieben von Emotionen, wie Gier, Neid und Hass, überwacht und ausgebeutet von einer PR-Maschinerie, die unablässig für Aufmerksamkeit sorgt. Eine psychosoziale Studie, wie es sie immer wieder in der Praxis gibt. Zum Beispiel am Hang des Mona Loa auf Hawaii, wo kürzlich im Rahmen des niederländischen Projekts Mars One das Zusammenleben auf engstem Raum nach einem Jahr beendet wurde. Das grösste Problem sei die Langeweile gewesen.

Warum tun sich Menschen solche Dinge an, um vielleicht einmal auf dem Mond oder Mars eine Basis aufzubauen? Vision und Hybris liegen nahe beieinander. Vielleicht lockt sie der Traum glücklicher Siedler, die in ihren Wohnkolonien die ausgebeutete, kaputte Erde hinter sich gelassen haben. Denn viel wahrscheinlicher ist es, dass wir unseren wunderbaren Planeten zugrunde richten, lange bevor wir durch irgendwelche astrophysikalische «Wurmlöcher» zu einer unwirtlichen Ersatzerde gelangen. «Zwei Dinge sind unendlich, das Universum und die menschliche Dummheit, aber beim Universum bin ich mir noch nicht ganz sicher», soll Einstein gesagt haben.

\section{Bildnachweis}

(C) Rfischia | Dreamstime.com

Literatur

1 Boyle TC. Die Terranauten. München: Carl Hanser Verlag; 2016. 